\section{$\underset{\substack{\text { hommes } \\ \text { \& migrations }}}{ }$}

\section{Hommes \& migrations}

Revue française de référence sur les dynamiques

migratoires

$1326 \mid 2019$

Londres et ses migrations

\title{
« Me voir comme un écrivain m'a vraiment aidé à façonner mon identité »
}

Entretien avec Hanif Kureishi

\section{Martin Evans}

\section{(2) OpenEdition}

Journals

Édition électronique

URL : https://journals.openedition.org/hommesmigrations/9572

DOI : $10.4000 /$ hommesmigrations.9572

ISSN : 2262-3353

Éditeur

Musée national de l'histoire de l'immigration

Édition imprimée

Date de publication : 1 juillet 2019

Pagination : 18-21

ISBN : 978-2-919040-46-9

ISSN : 1142-852X

Référence électronique

Martin Evans, « «Me voir comme un écrivain m'a vraiment aidé à façonner mon identité » », Hommes \& migrations [En ligne], 1326 | 2019, mis en ligne le 01 janvier 2022, consulté le 15 janvier 2022. URL:

http://journals.openedition.org/hommesmigrations/9572 ; DOI : https://doi.org/10.4000/

hommesmigrations.9572 


\section{«Me voir comme}

\section{un écrivain m’a vraiment aidé à façonner mon identité»}

\section{Entretien avec Hanif Kureishi}

\section{réalisé par Martin Evans,}

professeur d'histoire moderne européenne, président du comité directeur du Centre Middle East and North Africa de l'université du Sussex.

Hanif Kureishi, né le 5 décembre 1954 à Bromley (London), est un écrivain, scénariste et dramaturge britannique. Auteur de romans, de recueils de nouvelles, d'essais et de pièces de théâtre, il est l'un des représentants les plus célèbres de la nouvelle "école » d'écrivains britanniques d'origine étrangère. Son roman, Le Bouddha de banlieue (The Buddha of Suburbia, 1990) a reçu le Whitbread Award du meilleur premier roman et a bénéficié d'une adaptation en série télévisée. En 2004, Kureishi raconte dans Contre son cœur (My Ear at His Heart, 2004), un récit autobiographique, la genèse de sa propre inspiration. Son dernier roman paru en 2007 s'intitule: The Nothing (L'Air de rien).

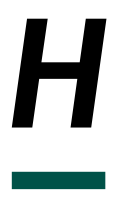

ommes \& Migrations: Comment étiez-vous perçu à l'école, dans les années 1950 et 1960 ?

Hanif Kureishi: Dès que je suis entré dans la cour de l'école, on m'a vu comme un «Paki». Mais, avec un peu de chance, ce regard qui vous catalogue «différent» vous pousse aussi à réfléchir à tout cela, au Pakistan, au colonialisme, au racisme... C'est souvent à l'adolescence que cette réflexion se met en place. Avant, cela reste une sorte d'énigme que vous ne comprenez pas.

Cette situation a agi comme un déclencheur: je me suis mis à lire, à essayer de comprendre, à discuter avec mon père et mes oncles, notamment de tout ce qui avait trait à Enoch Powell, car cette affaire était primordiale au sein de ma famille. Et puis, j'ai commencé à écrire sur le sujet, accumulant la matière qui allait donner naissance, beaucoup plus tard, à mon livre The Buddha of Suburbia'.

1. The Buddha of Suburbia est le premier roman écrit par Hanif Kureishi, paru en 1990. Voir, pour la traduction française, Hanif Kureishi, Le bouddha de banlieue, traduit de l'anglais par Michel Courtois-Fourcy, Paris, 10/18, 1993. 
H\&M: Étiez-vous le seul Anglais d'origine asiatique?

H. K.: À cette époque, j'étais le seul enfant asiatique scolarisé dans le sud de Londres. On ne voyait pas ça tous les jours - je veux dire, dans les années 1950, avant la vague d'émigration consécutive à l'expulsion par Idi Amin des Anglais asiatiques d'Ouganda, en 1972. Mon père était de ceux-là: Indien «exotique» cultivé, issu de la upper-class, considéré comme un véritable gentleman par les gens de la classe moyenne pauvre qui étaient nos voisins.

\section{H\&M: Quel fut l'impact du discours prononcé par Enoch Powell en 1968, et dans lequel il utilisait l'image d'un "fleuve de sang»?}

H. K.: Je me souviens que j'en parlais avec mon père et mes oncles: on avait là un membre du parti Tory - il ne s'agissait donc pas de ce racisme quotidien, comme on le rencontre sur les trottoirs - qui avait recours à un langage très violent pour annoncer, de manière assez loufoque, que l'homme noir était en train de damer le pion aux Blancs. J'avais l'impression qu'il retournait complètement la situation. La violence de son discours était inédite: on n'avait encore jamais vécu ça en Angleterre.

Mais, dans le même temps, grâce à mes lectures, j'étais au fait du mouvement Black Power, de Stokely Carmichael, du mouvement pour les droits civiques. Et j'écoutais Marvin Gaye, James Brown, de la soul - ce qui me permettait de comprendre le lien qu'entretenaient la musique et le combat pour les droits civiques.

L'un de nos grands modèles, à mon père et à moi, était le boxeur Cassius Clay, plus connu sous le nom de Mohammed Ali. C'était notre héros: sa manière de parler, de rapper, son arrogance. Mon père avait fait de la boxe en Inde, il en connaissait un rayon. On adorait le sport. On adorait aussi la politique, et on adorait les Noirs qui affirmaient leur liberté, comme Mohammed Ali. Ce dernier avait refusé de s'engager au Vietnam. Il n'hésitait pas à parler de la condition noire et de la condition blanche. C'était un artiste, il était extraordinaire.

\section{H\&M: Quelle a été l'importance de Marvin Gaye et de James Brown?}

H. $\mathbf{K}$ : : On se rendait compte que ces musiques avaient jailli d'un ghetto noir au milieu d'un monde blanc. Et voilà que Mick Jagger se mettait à danser comme James Brown. En remontant dans le passé, à partir de Led Zeppelin ou des Rolling Stones, on en apprenait beaucoup sur ces modèles qu'étaient le black blues, le rock'n'roll et Chuck Berry.

\section{H\&M: Et l'influence du black blues et de la soul ?}

H. K.: On comprenait que la culture pouvait naître de l'oppression. Cette musique sortait tout droit de l'église, du gospel, avec des voix comme Aretha Franklin. Et ainsi, à partir d'expériences personnelles, il était possible d'écrire des textes, de façonner des créations culturelles - et c'est ce que j'ai commencé à faire. Se battre, créer le débat politique. Et si vous vous sentiez une vocation artistique, ce qui, je crois, était mon cas, alors tous les ingrédients étaient réunis pour que vous vous mettiez à écrire.

La figure qui m'a le plus influencé fut sans conteste James Baldwin, écrivain éminemment singulier qui revendiquait clairement son identité d'homme noir, homosexuel et petit-fils d'esclaves - mais n'en devint pas moins un grand écrivain. En Angleterre, je ne pouvais m'identifier avec aucun écrivain de couleur. Mais un personnage comme Baldwin, si spirituel tout en étant rebelle, avec tant d'intelligence et de beauté, fut un immense exemple pour moi. Mon

2. James Baldwin, La prochaine fois, le feu, traduit de l'anglais par M. Sciama, Paris, Gallimard, coll. «Du monde entier», 1963; réédition, Paris Gallimard, coll. «Idées » no 165, 1968; réédition, Paris, Gallimard, coll. «Folio » no 2855, 1996. 
père a dû lire Baldwin, lui aussi: je me souviens que nous avions un exemplaire de La prochaine fois, le $\mathrm{feu}^{2}$ (The Fire Next Time) à la maison. Lisant ce livre, je comprenais qu'il était possible d'écrire à partir de son propre milieu, d'écrire la vie dans la rue. Et cette approche est devenue une manière de faire coïncider le personnel et le politique. J'ai eu envie d'écrire dès l'adolescence, de réfléchir à ma propre situation pour en parler par écrit. Mais j'ai mis longtemps à devenir écrivain, moi, le fils d'un homme qui avait grandi dans l'Inde coloniale et subi la colonisation.

\section{H\&M: Quelle était votre relation à la culture britannique?}

H. K.: Je l'adorais. J'ai grandi avec les émissions de la télévision anglaise telles que Steptoe and Son. Il y avait aussi la radio, bien sûr - surtout le John Peel Show -, et il y avait les Beatles. Je me rappelle le jour où j'ai acheté mon premier disque des Beatles, I Want to Hold your Hand (1963). J'en étais fou, tout comme j'étais fou des Rolling Stones, des Kinks, de toute cette génération de musiciens blancs qui furent infiniment importants pour moi et mes amis.

\section{H\&M: Comment l'expliquez-vous?}

H. K.: Ils étaient importants en ce qu'ils nous parlaient directement. C'étaient des gamins, comme nous. Keith Richards venait de Deptford, Jimmy Page et Eric Clapton du Sud-Est de l'Angleterre. Comme nous, c'étaient de simples garçons qui s'étaient mis à la guitare en écoutant Muddy Waters. Issus de la petite classe moyenne, ces enfants avaient fréquenté les Beaux-Arts, et ils avaient appris le blues pour ensuite le transformer en quelque chose de complètement différent... On écoutait les Stones, et on se disait: voilà, c'est ça qu'il faut faire. C'était tellement libérateur!

\section{H\&M: Comment avez-vous vécu votre enfance à Bromley, dans la banlieue de Londres?}

H. K.: Dans les années 1960, tout était limité dans les banlieues. Vraiment limité, vraiment froid. Et pendant ce temps-là, une poignée d'heureux élus se la coulaient douce à Londres. Je voulais les rejoindre.

\section{H\&M: En quoi la banlieue était-elle limitée, restreinte?}

H. K.: Les destins de ses habitants étaient déjà tout tracés. Enfant de cette classe moyenne pauvre, on vous formait pour vous destiner à un métier dans l'assurance ou la fonction publique. Ou bien on vous envoyait aux
Beaux-Arts. Ou dans la publicité, comme ce fut le cas pour David Bowie [lequel fréquenta la même école secondaire que Hanif Kureishi dix ans avant celui-ci]. vous voyez que notre horizon était restreint.

Mais, même dans cette banlieue de malheur, ce trou perdu, on pouvait aller acheter des disques à Bromley. On pouvait aussi pousser jusqu'à Londres pour en dénicher. Et puis on avait la radio dans nos chambres. Je passais des heures à tourner les molettes pour capter Radio Luxembourg. Le John Peel Show, que diffusait la BBC, fut aussi très important. Cette émission nous ouvrait les portes sur le monde, sur tout ce qui se passait «à l'extérieur».

\section{H\&M: Le souvenir de la Seconde Guerre mondiale était-il encore très présent?}

H. K.: Le sud de Londres avait été ravagé par les bombardements. Ma mère et ma grand-mère avaient vécu à Londres pendant la guerre, elles en parlaient beaucoup. La guerre était toujours présente. Le Londres des années 1960 était comme en chute libre. C'était froid, c'était sale. Mais ça profita à mon père, puisqu'il put acheter une maison pour pas trop cher et s'y installer avec sa famille.

\section{H\&M: Comment avez-vous été influencé par la culture de la jeunesse dans les années 1960 ?}

H. K.: Dans mon école, les élèves se divisaient en trois grands groupes: les mods, les rockers et les hippies. Moi, je faisais partie des hippies, je m'intéressais beaucoup à la période centrale des Beatles, cette phase où ils sont partis en Inde et ont commencé à faire de la musique expérimentale. Je me revois en train de me balader à l'école, enguirlandé de fleurs. J'adorais aussi la musique californienne, comme The Mammas and the Pappas. Reste que l'atmosphère dans le sud de Londres était étouffante, et pas seulement à cause du racisme: il y avait aussi les gangs. On était constamment menacés d'agression.

\section{H\&M: Qu'en était-il des skinheads?}

H. K.: Nombre de mes amis sont passés dans les rangs des skinheads, arborant le fameux jean Levi's tenu par des bretelles. C'est à cette époque que le racisme s'est encore plus formalisé pour devenir un vrai mouvement. Je me souviens que je devais protéger mon père quand il rentrait du travail, à cause des skinheads qui traînaient près de notre station. 


\section{H\&M: Quelle importance avaient le ska et le reggae?}

H. K.: J'allais souvent danser au son du reggae, du ska et du bluebeat. Les enfants blancs faisaient copain-copain avec les Antillais, les West Indians, comme on les appelait - mais avec les enfants asiatiques, c'était un peu différent. Nous, on mangeait du curry et on parlait une autre langue. Ce qui était aussi lié à la différence de classe: je venais d'une famille d'intellectuels, tandis que les skinheads et les West Indians étaient issus de milieux que nous considérions comme incultes. La classe sociale jouait donc un rôle prépondérant dans tout cela. La plupart des West Indians étaient employés par la sécu anglaise, le métro de Londres ou les services de bus, tandis que les Asiatiques ouvraient en général des restaurants et des boutiques.

\section{H\&M: Comment votre père percevait-il la culture antillaise?}

H. K.: Mon père raffolait de musique caribéenne. Et il adorait aussi le cricket. Nous venions d'une famille d'amateurs de cricket. Mon père avait une admiration sans bornes pour l'équipe de cricket des Caraïbes. Il adulait la culture caribéenne en général - du moins ce qu'il en connaissait, c'est-à-dire la musique et surtout le cricket.

H\&M: Comment cette enfance dans les années 1950, 1960 et 1970 a-t-elle influencé votre écriture?

H. K.: Les premiers livres que j'ai écrits étaient des versions antérieures du Buddha of Suburbia. Ils décrivaient la situation d'un enfant asiatique grandissant dans la banlieue sud de Londres. Je commençais à me définir, à me demander qui j'étais. Après avoir été hippie, je suis passé dans le camp des punks - j'ai donc aussi fait partie de cette culture de la jeunesse blanche -, alors qu'en fait, tous mes oncles et tantes vivaient au Pakistan et venaient nous rendre visite chaque été en Angleterre. La question était donc de savoir comment écrire un livre qui brasserait tous ces éléments. Ce que personne n'avait encore fait à l'époque. C'est du moins ce que je croyais.

J'avais quatorze ou quinze ans quand j'ai commencé à écrire. Je voulais vraiment devenir écrivain. Me voir comme un écrivain m'a vraiment aidé à façonner mon identité. Au lieu de me considérer comme un «métis», un «Paki», un gamin qui ne trouverait sa place nulle part, je me définissais comme un écrivain, je me mettais sur le même plan que James Baldwin, et cette catégorisation m'a vraiment aidé. C'est elle qui m'a donné un avenir. C'était une identité que je m'étais créée de toutes pièces.

Imaginer que je pourrais devenir un artiste aussi grandiose que les Rolling Stones ou les Who: voilà ce qui m'a donné un avenir. Ils créaient en permanence, tous les jours. Je ne suis pas musicien, mais la mobilité sociale qui allait de pair avec la pop me permettait de créer. Je m'identifiais avec cette mobilité - et cette identification, je l'exprimais par mon écriture. 